\title{
PRINCIPAIS ALTERAÇÕES NO LEITE POR AGENTES CAUSADORES DE MASTITE NO REBANHO CAPRINO DOS ESTADOS DE MINAS GERAIS E RIO DE JANEIRO
}

\author{
J.F. Almeida ${ }^{1}$, M.H.C. Aquino ${ }^{1}$, H. Magalhães ${ }^{2}$, \\ E.R. Nascimento ${ }^{1}$, V.L.A. Pereira ${ }^{1}$, T. Ferreira ${ }^{1}$, M.L. Barreto ${ }^{1}$ \\ ${ }^{1}$ Universidade Federal Fluminense, Faculdade de Veterinária, Departamento de Saúde Coletiva Veterinária \\ e Saúde Pública, Rua Vital Brasil Filho, 64, CEP 24230-340, Niterói, RJ, Brasil. E-mail: maryhel@uol.com.br
}

\section{RESUMO}

A mastite subclínica caprina ocasiona prejuízos econômicos em decorrência do descarte, dos gastos com medidas terapêuticas e da redução da quantidade e qualidade do leite e seus derivados. Nesse estudo, 129 amostras de leite de cabra in natura, provenientes de 11 propriedades foram avaliadas pelo teste da caneca telada, California Mastitis Test (CMT), exame bacteriológico, pesquisa de Mycoplasma spp. e pela determinação dos parâmetros físico-químicos. No teste da caneca telada e no CMT, 3,1\% e 4,6\% das amostras foram positivas, respectivamente. No exame bacteriológico, $57,4 \%$ das amostras foram positivas e o patógeno mais frequente foi Staphylococcus coagulase negativa com 56\% das cepas resistentes à penicilina e $100 \%$ de sensíveis à gentamicina. Mycoplasma spp. não foi identificado nas amostras. O diagnóstico da mastite subclínica pelo CMT e pelo exame bacteriológico diferiu de forma significativa e não houve associação entre o número de UFC/mL obtidas no exame microbiológico e o resultado do CMT (Qui-quadrado p < 0,05). Os parâmetros físico-químicos diferiram significativamente entre os rebanhos (ANOVA, TukeyKramer, $\mathrm{p}<0,05$ ) e a gordura foi o constituinte que demonstrou maior amplitude, sendo que $63,4 \%$ dos rebanhos apresentaram os valores abaixo do exigido pela legislação brasileira. Não houve associação significativa entre a presença de mastite diagnosticada pelo exame bacteriológico e os valores obtidos para os parâmetros físico-químicos (t-Student $\mathrm{p}>0,05$ ). Com base nos resultados obtidos, recomenda-se a associação do exame bacteriológico quando na utilização do CMT para diagnóstico da mastite subclínica caprina.

PALAVRAS-CHAVE: Leite de cabra, mastite, parâmetros físico-químicos, microbiológicos.

\begin{abstract}
MAJOR CHANGES IN MILK BY MASTITIS CAUSATIVE AGENTS IN GOAT HERD FROM THESTATES OF MINAS GERAIS AND RIODE JANEIRO, BRAZIL. Goat mastitis causes significant economic losses due to the discarding of milk, costs of drugs and veterinary care, reducing the quantity and quality of milk and dairy products. In this study, 129 raw milk samples from 11 goat farms were investigated by the Tamis test, California mastitis test (CMT), bacteriological exam, presence of Mycoplasma spp. and physicochemical parameters. Seven (4.6\%) and four samples (3.1\%) were positive by CMT and Tamis test respectively. Bacteriological exam was positive from $57.4 \%$ of samples and coagulase-negative Staphylococcus was the most frequent bacteria isolated showing $56 \%$ of the strains resistant to penicillin and no resistance to gentamicin. Negative results were obtained from traditional culture as well as by PCR for Mycoplasma spp. The diagnosis of mastitis, the bacteriological exam and the CMT results differed significantly and no association was observed (chi squared, $\mathrm{p}<0.05$ ). Fat was the constituent with more variations and $63.4 \%$ of the herds did not meet the minimum requirement according to Brazilian government criteria for this constituent. There was no significant association between mastitis and the physicochemical parameters (t-Student, $\mathrm{p}>0.05$ ). The physicochemical parameters differed significantly (ANOVA, Tukey-Kramer, $\mathrm{p}<0.05$ ) among the herds. These results indicate the need to associate microbiological exam when the CMT is used for the diagnosis of goat mastitis.
\end{abstract}

KEY WORDS: Goat milk, mastitis, physicochemical parameters, microbiological.

${ }^{2}$ Pesagro-Rio, Laboratório de Biologia Animal, Niterói, RJ, Brasil. 


\section{INTRODUÇÃO}

O leite de cabra tem sido bastante utilizado como alternativa para alimentação de crianças e adultos sensíveis ou alérgicos ao leite de vaca e sua qualidade é definida por seus parâmetros físico-químicos e microbiológicos estabelecidos com o objetivo de fixar condições de produção, identidade e requisitos mínimos de qualidade para consumo.

A mastite em caprinos é predominantemente subclínica e os patógenos comumente relacionados com infecções intramamárias são Staphylococcus e Streptococcus, considerados os principais micro-organismos contagiosos, além de agentes ambientais como enterobactérias e Mycoplasma spp. (МотA., 2008; Peiхoтo et al., 2010; Dal Pozzo et al., 2011).

Além das alterações microbiológicas, outras mudanças na composição do leite podem ser resultantes de mastite como redução do teor de lactose, caseína, nível de $\mathrm{Ca}$, $\mathrm{K}$ e Fe e aumento de $\mathrm{Na}$ e $\mathrm{Cl}$. Essas alterações influem no rendimento industrial e no valor nutritivo dos produtos lácteos, sobretudo queijos e iogurte (Megersa et al., 2010; Mungatana et al., 2011).

Embora a regiãoSudeste represente apenas $4 \%$ do efetivo caprino no Brasil, destaca-se pela representatividade de seus estados no agronegócio caprino leiteiro, sendo responsável por, aproximadamente, $54,6 \%$ do total de leite de cabra produzido no país com uma cadeia produtiva bastante organizada (CosTA, 2009). As raças leiteiras adotadas são especializadas (Saanen, Alpina e Toggenburg) ou mestiças, mantidas em galpões e com alimentação fornecida no cocho.

O objetivo desse estudo foi investigar a ocorrência de patógenos causadores de mastite e avaliar a qualidade físico-química de amostras de leite in natura de rebanhos caprinos situados nos estados do Rio de Janeiro e de Minas Gerais.

\section{MATERIAL E MÉTODOS}

Neste estudo foram avaliadas 129 amostras de leite de cabra obtidas de 11 propriedades, identificadas alfabeticamente de A a K, localizadas nos municípios de Niterói, Nova Friburgo e Paracambi no Estado do Rio de Janeiro, e em Além Paraíba, Belmiro Braga, Coronel Pacheco, Leopoldina e Viçosa em Minas Gerais. Os rebanhos eram constituídos de animais puros e/ou mestiços das raças Saanen e Parda Alpina, com ou sem sintomatologia clínica de mastite, em diferentes estágios de lactação e submetidos à ordenha do tipo manual ou mecânica.

O diagnóstico de mastite clínica foi realizado pelo exame clínico do animal, da glândula mamária e retirada dos três primeiros jatos de leite em caneca telada para a observação de grumos, coágulos, pus, sangue ou leite aquoso. Para o diagnóstico de mastite subclínica foi aplicado o "California Mastitis Test" (CMT) (NATIONAL..., 1999) em cada metade mamária. Escores aritméticos foram atribuídos às diferentes reações do $\mathrm{CMT}$, sendo 0 , para as reações negativas, $1+$ (fracamente positivas), $2+$ (positivas) e $3+$ (fortemente positivas), determinadas pela viscosidade formada entre o reagente e o leite.

Para o exame bacteriológico, foram coletados $50 \mathrm{~mL}$ de leite em frascos estéreis por animal e 200 $\mathrm{mL}$ em frascos descartáveis para os exames físicoquímicos, acondicionados em caixa isotérmica com gelo e encaminhados aos laboratórios no mesmo dia. Alíquotas de 0,1mL de cada amostra de leite foram semeadas em Agar sangue ovino (5\%) desfibrinado, agar sal manitol (Merck ${ }^{\circledR}$ ) eagar eosina azul de metileno $\left(\right.$ Merck $\left.^{\circledR}\right)$ e incubadas em condições de aerobiose, a $37^{\circ} \mathrm{C}$ por 24 a $48 \mathrm{~h}$. Nos cultivos contendo mais de cinco colônias com uma única morfologia, procedeuse a contagem de colônias, coloração de Gram e a identificação de todos os isolados (McDougall et al. 2001; National... (1999). Adicionalmente, as cepas de Staphylococcus spp. isoladas foram submetidas ao teste de sensibilidade antimicrobiana in vitro frente à penicilina (10 UI), ampicilina $(10 \mathrm{mcg})$, cefalexina (30 mcg), enrofloxacina (5 mcg), eritromicina (15 $\mathrm{mcg})$, gentamicina (10 mcg), novobiocina (5 mcg), oxacilina (1 mcg), sulfametoxazol/trimetoprim ( 25 $\mathrm{mcg}$ ) e tetraciclina $(30 \mathrm{mcg}$ ) pelo método de difusão em discos (NATional.., 2003).

Paralelamente, foi feita pesquisa de Mycoplasma spp. pelo cultivo (CONTRERAs et al., 1995) e pela PCR (AlmeIDAetal., 2007) e de M. mycoides cluster conforme Persson et al. (1999). A extração de DNA de cada amostra de leite foi realizada pelo método de fenol/ clorofórmio (SАMBROOK et al., 1989). Como controles positivos da PCR foram utilizadas as cepas ATCC de M. agalactiae GM139e M. mycoides subsp. mycoides "Large Colony". Os produtos amplificados foram submetidos à eletroforese em gel de agarose e a visualização de "amplicons" feita em transiluminador.

As seguintes análises físico-químicas foram feitas segundo os Métodos Analíticos Oficiais FísicoQuímicos para o Controle de Leitee Produtos Lácteos (BrasiL, 2003) e segundo o Regulamento Técnico de Produção, Identidade e Qualidade do Leite de Cabra (BRASIL, 2000): acidez titulável com solução Dornic, teor de gordura pelo método de Gerber, teor de caseína pelo método Sorensen-Walker modificado, índice crioscópico, teor de extrato seco total com o disco de Ackerman, teor de cloretos pelo método mercurométrico, densidade $15^{\circ} \mathrm{C}$ e o teor de lactose pelo método Lane-Eynon.

A seleção dos rebanhos foi feita por amostragem probabilística, mas em cada rebanho os caprinos foram selecionados ao acaso. Para a comparação entre as médias obtidas para os diferentes parâmetros físico-químicos, entre e dentre os rebanhos, foi 
utilizada a análise de variância (ANOVA) seguida do Teste de Tukey Kramer. A associação entre o CMT e o exame bacteriológico e entre o CMT e a contagem microbiana foi investigada pelo teste do Qui-quadrado de McNemar. A associação entre exame bacteriológico e parâmetros físico-químicos foi investigada pelo testet-Student (THRUSFIELD, 2004).

\section{RESULTADOS E DISCUSSÃO}

Foram obtidos resultados positivos nos testes de CMT e caneca telada em 4,6\% (7/129) e3,1\% (4/129) das amostras, respectivamente. Somente os escores ${ }^{3} 2+$ foram considerados como infecção, devido à presença de maior número de células somáticas no leite dessa espécie (МотA, 2008).

Dentre as $74(57,4 \%)$ amostras positivas no cultivo, o patógeno mais prevalente foi Staphylococcus coagulase negativa presente em 59 amostras $(79,7 \%)$, seguido de Streptococcus spp. em seis amostras (8\%), Proteus vulgaris, Pseudomonas spp. e E. coli em três amostras (4\%), Staphylococcus coagulase positiva em duas amostras $(2,7 \%)$ e Klebsiella spp. em uma amostra $(1,3 \%)$. Os cultivos apresentaram contagem de colônias variando entre 0 e $10^{3} \mathrm{UFC} / \mathrm{mL}$ em 16 amostras (12,4\%), entre $10^{3}$ e $10^{4} \mathrm{UFC} / \mathrm{mL}$ em 37 amostras $(28,7 \%)$ e entre $10^{4} \mathrm{UFC} / \mathrm{mLe} 3 \times 10^{4} \mathrm{UFC} /$ mL em 21 amostras (16,3 \%). Dez cultivos (7,7\%) foram considerados contaminados, pois apresentaram mais de três tipos de colônias. Em 55 amostras $(42,6 \%)$ não foi observado crescimento bacteriano nos meios semeados.

Neste estudo foi observada baixa positividade no CMT (4,6\%). Vilanova et al. (2008) também observaram cerca de $7 \%$ das amostras de leite caprino positivas no CMT a partir do escore ${ }^{3} 2+$. Segundo CONTRERAs et al. (2007), a incidência de mastite subclínica em pequenos ruminantes pode variar entre 5 a $30 \%$. O exame bacteriológico nesse estudo foi negativo em $42,6 \%$ das amostras. Регхото et al. (2010) não observaram crescimento bacterianoem $82,1 \%$ das amostras de leite de caprinos analisadas e VILANOVA et al. (2008) não isolaram micro-organismos das amostras de leite do rebanho caprino investigado. Esses resultados podem ser devido a um maior nível fisiológico de células somáticas no leite e a um percentual elevado de neutrófilos, fazendo com que o leite caprino apresente naturalmente baixo conteúdo bacteriano, pois a glândula apresenta uma maior resistência às infecções ambientais (PAAPE; CAPUCO, 1997). Na mastite, o número de colônias por mililitro de leite é muito baixo, não existindo relação estreita entre a ocorrência de mastite e a contagem bacteriana do leite. Uma exceção, neste caso, seria a mastite causada por Streptococcus agalactiae, Streptococcus uberis, Escherichia coli e Mycoplasma spp., com conta- gens desses micro-organismos até $10^{7} \mathrm{UFC} / \mathrm{mL}$ por metade mamária (CONTRERAs et al., 2007).

Neste estudo, dentre as sete amostras positivas no CMT, três continham Staphylococcus coagulase negativa, duas continham E. coli, uma continha Klebsiella spp. e em uma amostra não foi obtido crescimento bacteriano. Não foi observada associação entre o resultado do CMT e o resultado do exame bacteriológico e da contagem microbiana $(p>0,05)$. Регхото etal. (2010) também observaram uma baixa correlação entre o exame bacteriológico e o CMT em estudos realizados em rebanhos caprinos no nordeste.

O isolamento de Staphylococcus coagulase negativa em $45,7 \%$ das amostras confirma o fato de serem esses agentes os mais frequentemente encontrados na glândula mamária dos caprinos (CONTRERAs et al., 2007; GOTTARDI et al., 2008). Somente em duas amostras foi isolado Staphylococcuscoagulase positiva. Embora apenas contagens elevadas de $S$. aureus $\left(10^{5} \mathrm{UFC} / \mathrm{g}\right)$ sejam consideradas como risco da presença de enterotoxina nos alimentos, os Staphylococcus coagulase negativa também tem sido apontados como potencialmente enterotoxigênicos, podendo vira ter algum significado para a segurança dos alimentos (GOTTARDI et al., 2008).

A resistência antimicrobiana observada para as 59 cepas de Staphylococcus coagulase negativa foi de $56 \%(33 / 59)$ para ampicilina e penicilina, 10,2\% (6/59) para tetraciclina, 3,4\% (2/59) para oxacilina, enrofloxacina, sulfametoxazol/trimetoprim, eritromicina, $1,7 \%(1 / 59)$ para cefalexina e todas foram sensíveis à gentamicina. Dentreas duascepas coagulase positivas isoladas de propriedades distintas, uma apresentou resistênciaà ampicilina, penicilina, oxacilina ecefalexina, enquanto a outra cepa foi resistente à tetraciclina e ampicilina. Essa elevada taxa de resistência frente às penicilinas foi também observada por outros autores ao investigar o perfil de sensibilidade de cepas de Staphylococcus spp. isoladas de leite caprino (Lima JúNIOR et al., 1993; RAPINI et al., 2005).

Não foi identificada a presença de Mycoplasma spp. pelo cultivo e pela PCR e, embora esse agente seja responsável pela agalaxia contagiosa, já descrita no Brasil (AzEVEDo et al., 2006), os animais dos rebanhos estudados não apresentavam características de mastite por Mycoplasma spp., como sedimentos no leite, queda brusca na produção e elevada contagem de células somáticas avaliadas pelo CMT.

Os parâmetros físico-químicos acidez, caseína, cloretos, densidade, extrato seco total e desengordurado, gordura, índice crioscópico e lactose diferiram significativamente $(\mathrm{p}<0,05)$ entre os rebanhos (Tabela1). Alguns rebanhos não atenderam aos padrões exigidos para acidez $(\mathrm{K})$, gordura $(\mathrm{C}, \mathrm{E}, \mathrm{F}, \mathrm{G}, \mathrm{H}, \mathrm{I}, \mathrm{J})$, densidade $(\mathrm{H})$, lactose $(\mathrm{A})$, índice crioscópico (D) e sólidos não gordurosos (A,E,F,G,H) estabelecidos pela Instrução Normativa $\mathrm{N}^{\circ} 37$ de 31 de outubro de 2000 (BRASIL, 2000). 
Tabela 1 - Valores médios dos parâmetros físico-químicos do leite de cabra por rebanho, em 11 propriedades dos estados de Minas Gerais e do Rio de Janeiro.

\begin{tabular}{cccccccccc}
\hline \multirow{2}{*}{ Rebanhos } & \multicolumn{7}{c}{ Médias dos parâmetros físico-químicos } \\
\cline { 2 - 10 } & Acidez & Caseína & $\mathrm{G}^{1}$ & $\mathrm{D}^{2}$ & $\mathrm{IC}^{3}$ & Cloreto & EST $^{4}$ & ESD $^{5}$ & Lactose \\
\hline A & 17,47 & 2,32 & 3,2 & 1028,3 & $-0,564$ & 0,21 & 11,17 & 7,97 & 4,05 \\
B & 15,35 & 2,65 & 3,6 & 1030,4 & $-0,575$ & 0,69 & 12,15 & 8,51 & 5,18 \\
C & 13,00 & 2,45 & 2,7 & 1029,6 & $-0,575$ & 0,22 & 10,93 & 8,23 & 4,71 \\
D & 16,26 & 2,43 & 3,3 & 1030,3 & $-0,593$ & 0,24 & 11,72 & 8,50 & 5,05 \\
E & 13,54 & 2,25 & 1,9 & 1030 & $-0,561$ & 0,25 & 9,87 & 7,95 & 5,08 \\
F & 13,56 & 2,32 & 2,2 & 1029,6 & $-0,578$ & 0,21 & 10,36 & 8,12 & 4,44 \\
G & 14,24 & 2,24 & 2,4 & 1029,4 & $-0,565$ & 0,19 & 10,51 & 8,10 & 4,96 \\
H & 14,38 & 2,19 & 1,6 & 1027,6 & $-0,558$ & 0,22 & 9,13 & 7,49 & 5,02 \\
I & 17,34 & 2,56 & 2,8 & 1030 & $-0,569$ & 0,20 & 11,09 & 8,33 & 5,35 \\
J & 17,06 & 2,61 & 2,2 & 1030,2 & $-0,574$ & 0,15 & 10,46 & 8,26 & 5,31 \\
K & 19,48 & 2,78 & 2,9 & 1031,3 & -6 & 0,12 & 11,68 & 8,69 & 4,85 \\
\hline Geral & 15,61 & 2,44 & 2,62 & 1029,7 & $-0,571$ & 0,25 & 10,82 & 8,19 & 4,91 \\
\hline
\end{tabular}

${ }^{1}$ Gordura.

${ }^{2}$ Densidade.

${ }^{3}$ Índice crioscópico.

${ }^{4}$ Extrato seco total.

${ }^{5}$ Extrato seco desengordurado.

${ }^{6}$ Análise não realizada.

A composição química do leite de cabra é bastante variável em função de múltiplos fatores, tais como raça, período de lactação, clima, estação do ano, alimentação, idade do animal e produção de leite. $\mathrm{O}$ estágio da lactação pode influenciar na sua constituição, pois com o seu avançar podem ser observadas quedas nos teores de sólidos totais, gordura elactose, enquanto os teores de proteína podem permanecer praticamente estáveis (GOMEs et al., 2004). O teor de lactose também é influenciado pelos diferentes níveis de concentrado da dieta, mas se constitui em um dos nutrientes mais estáveis na composição química do leite, estando diretamente relacionado à regulação da pressão osmótica, de modo que maior produção de lactose determina maior produção de leite (QueIROGA et al., 2007).

Nesse estudo a gordura foi o constituinte que demonstrou maior amplitude. O teor de gordura é o constituinte do leite que possui maior variação, sendo principalmente influenciado por fatores nutricionais, turno da ordenha e raça. Conforme estabelecido na legislação vigente (BRASIL, 2000), valores inferiores a 2,9\% de gordura são admitidos para as variedades de leite integral e semidesnatado, mediante comprovação de que o teor médio de gordura de um determinado rebanho não atinja esse nível. Nesse estudo, o teor médio de gordura encontrado foi abaixo dessa média, ou seja, 2,6\% (Tabela 1). Algumas raças se caracterizam pela alta produção de leite com baixo teor de gordura como a raça Saanen investigadas nesse estudo. Teores médios de gordura obtidos em estudos no Brasil variam de 3,5\% a 5,5\% (QueIroga et al., 1998).
Os teores de EST, caseína e cloretos não foram estabelecidos pela legislação brasileira para o leite caprino. Esses parâmetros podem ser comparados com os obtidos por outros autores. BARROS; LEITÃO (1992) obtiveram valores médios de 12,1\%, 2,5\% e $0,2 \%$ para EST, caseína e cloretos, respectivamente. Nesse estudo, o rebanho B apresentou índice de cloreto elevado $(0,68 \%)$ e nesse rebanho duas amostras foram positivas ao CMT. Na mastite, embora as modificações do leite sejam significativas, ocorre um equilíbrio da pressão osmótica intramamária em relação ao sangue e, consequentemente, a diminuição da lactose no leite proveniente de vacas com mastite é compensada pelo aumento do cloro. O EST é representado pela gordura, açúcar, proteínas e sais minerais, sendo um indicador importante devido à exigência de padrões mínimos no leite e pela influência no rendimento de produtos lácteos (Pereira et al., 2005). Nesse estudo, os rebanhos C, E, F, G, H e J apresentaram valores médios de EST bem abaixo de $11,8 \%$ encontrado por Pereira et al. (2005) e o valor médio da caseína foi semelhante ao observado por outros autores (Tabela 1) (BARROS; LeITÃo, 1992; PrATA et al., 1998;).

\section{CONCLUSÕES}

Foi observada uma baixa prevalência de mastite de acordo com o CMT e exame bacteriológico nos rebanhos caprinos investigados e Staphylococcus coagulase negativa foi o principal patógeno envolvido na mastite caprina. O diagnóstico pelo CMT e pelo 
exame bacteriológico diferiu de forma significativa e recomenda-se a associação do exame bacteriológico quando na utilização do CMT para diagnóstico da mastite subclínica caprina. Alguns rebanhos não atenderam aos padrões físico-químicos exigidos para os constituintes do leite de acordo com a legislação brasileira. Atenção especial deve ser dada às exigências nutricionais das fêmeas em lactação para obtenção de melhor composição química do leite e cumprimento dos padrões nacionais exigidos para esse produto.

\section{AGRADECIMENTOS}

Ao Conselho Nacional de Desenvolvimento Científico e Tecnológico (CNPq) e à Fundação de Amparo à Pesquisa do Estado do Rio de Janeiro (FAPERJ), pelo suporte financeiro.

\section{REFERÊNCIAS}

ALMEIDA, J.F.; NASCIMENTO, E.R.; PEREIRA, V.L.A.; BARRETO, M.L.; CAMPOS, C.A.M.; AZEVEDO, E.O. Reação em Cadeia da Polimerase (PCR) no diagnóstico de micoplasmose caprina a partir de cultivos estocados em glicerina. Revista Brasileira de Medicina Veterinária, v.29, p.54-57, 2007.

AZEVEDO, E.O.; ALCÂNTARA, M.D.B.; NASCIMENTO, E.R.; TABOSA, I.M.; BARRETO, M.L.; ALMEIDA, J.F.; ARAÚJO, M.D.O.; RODRIGUES, A.R.O.; RIETCORREA, F.; CASTRO, R.S. Contagious Agalactia by Mycoplasma agalactiae in small ruminants in Brazil: first report. Brazilian Journal of Microbiology, v.37, p.576-581, 2006.

BARROS, G.C.; LEITÃO, C.H.S. Influência da mastite sobre as características físico-químicas do leite de cabra. Pesquisa Veterinária Brasileira, v.12, n.3/4, p.45-48, 1992.

BRASIL. Ministério da Agricultura e do Abastecimento. Secretaria Nacional de Defesa Agropecuária. Instrução Normativa $n^{\circ} 37$ de 31 de outubro de 2000. Regulamento Técnico de Produção, Identidade e Qualidade do Leite de Cabra. Diário Oficial da União, Brasília, 8 de novembro de 2000.

BRASIL. Ministério da Agricultura, Pecuária e Abastecimento. Instrução Normativa ${ }^{\circ} 22$ de 14 de Abril de 2003. Métodos Analíticos Oficiais Físico-Químicos para controle de leite e produtos lácteos. Diário Oficial da União, Brasília, 2 de maio de 2003. Seção I, p.3.

CONTRERAS, A.; CORRALES, J.C.; SIERRA, D.; MARCO, J. Prevalence and aetiology of non-clinical intramammary infection in Murciano-Granadina goats. Small Ruminant Research, v.17, p.71-78, 1995.
CONTRERAS, A.; SIERRA, D.; SÁNCHEZ, A.; CORRALES, J.C.; MARCO, J.C.; PAAPE, M.J.; GONZALO, C. Mastitis in small ruminants. Small Ruminant Research, v.68, p.145-153, 2007.

COSTA, A.L. da Leite caprino: um novo enfoque de pesquisa. Sobral: Embrapa Caprinos e Ovinos. Disponível em: <http://www.cnpc.embrapa.br/>. Acesso em: 20 out. 2009.

DAL POZZO, M.; VIEGAS, J.; SANTURIO, D.F.; ROSSATO, L.; SOARES, I.S.; ALVES, S.H.; COSTA, M. Atividade antimicrobiana de óleos essenciais de condimentos frente a Staphylococcus spp. isolados de mastite caprina. Ciência Rural, v.41, p.667-672, 2011.

GOMES, V.; LIBERA, A.M.M.P.D.; MADUREIRA, K.M.; ARAUJO, W.P. Influência do estágio de lactação na composição do leite de cabras (Capra hircus). Brazilian Journal of Veterinary Research and Animal Science, v.41, p.339-342, 2004.

GOTTARDI, C.P.T.; MURICY, R.F.; CARDOSO, M.; SCHMIDT, V. Qualidade higiênica de leite caprino por contagem de coliformes e estafilococos. Ciência Rural, v.3, p.743-748, 2008.

LIMA JUNIOR, A.D.; NADER FILHO, A.; VIANNI, M.C.E. Sensibilidade "in vitro" dos Staphylococcus aureus e Staphylococcus coagulase negativos, isolados em casos de mastite caprina, à ação de antibióticos e quimioterápicos. Arquivo Brasileiro de Medicina Veterinária e Zootecnia, v.45, p.291-296, 1993.

McDOUGALL, S.; MURGOUGH, P.; PANKEY, W.; DELANEY, C.; BARLOW, J.; SCRUTON, D. Relationship among somatic cell count, California mastitis test, impedance and bacteriological status of milk in goats and sheep in early lactation. Small Ruminant Research, v.40, p.245-254, 2001.

MEGERSA, B.; TADESSE, C.; ABUNNA, F.Ocurrence of mastitis and associated risk factors in lactating goats under pastoral management in Borana, Southern Ethiopia. Tropical Animal Health and Production, v.42, p.12491255, 2010.

MOTA, R.A. Aspectos Epidemiológicos, diagnóstico e controle das mastites em caprinos e ovinos. Tecnologia \& Ciência Agropecuária, v.2, n.3, p.57-61, 2008.

MUNGATANA, N.K.; NGURE, R.M.; SHITANDI, A.; ONYIEGO, B.; MUTUMA, M. Effect of experimental Staphylococcus aureus mastitis on compositional quality of goat milk. International Journal of Dairy Technology, v.64, p-360-364, 2011.

\section{NATIONAL COMMITTEE FOR CLINICAL} LABORATORY STANDARDS (US). Performance standards for antimicrobial susceptibility testing: 13th. Informational supplement, Wayne, Pa.: NCCLS, 2003. (NCCLS Document M100-S13). 
NATIONAL MASTITIS COUNCIL (US). Laboratory handbook on bovine mastitis. Madison, WI: NMC, 1999. 222p.

PAAPE, M.J.; CAPUCO, A.V. Cellular defense-mechanism in the udder and lactation of goat. Journal of Animal Science, v.75, p.556-565, 1997.

PEIXOTO, R.M.; FRANÇA, C.A.; SOUZA JÚNIOR, A.F.; VESCHI, J.L.; COSTA, M. Etiologia e perfil de sensibilidade antimicrobiana dos isolados bacterianos da mastite em pequenos ruminantes e concordância de técnicas empregadas no diagnóstico. Pesquisa Veterinária Brasileira, v.30, p.735-740, 2010.

PEREIRA, R.A.G.; QUEIROGA, R.C.R.E.; VIANNA R.P.T.; OLIVEIRA, M.E.G. Qualidade química e física do leite de cabra distribuído no Programa Social "Pacto Novo Cariri" no Estado da Paraíba. Revista do Instituto Adolfo Lutz, v.64, p.205-211, 2005.

PERSSON, A.; PETERSSON, B.; BOLSKE, G.; JOHANSSON, $\mathrm{K}$. Diagnosis of contagious bovine pleuropneumonia by pCR-Laser-Induced Fluorescence and PCR-Restriction Endonuclease Analysis Based on the 16S rRNA Genes of Mycoplasma mycoides subsp. mycoides SC. Journal of Clinical Microbiology, v.37, p.3815-3821, 1999.

PRATA, L.F.; RIBEIRO, A.C.; REZENDE, K.T.; CARVALHO, M.R.B.; RIBEIRO, S.D.A.; COSTA, R.G. Composição, perfil nitrogenado e características do leite caprino (Saanen). Região Sudeste. Brasil. Ciência e Tecnologia de Alimentos, v.18, p.428-432, 1998.
QUEIROGA, R.C.R.E.; TRIGUEIRO, I.N.S.; FERREIRA, M.C.C. Caracterização do leite de cabras mestiças do Brejo Paraibano, durante o período de lactação. Higiene Alimentar, v.12, p.77-80, 1998.

QUEIROGA, R.C.R.E.; COSTA, R.G.; BISCONTINI, T.M.B.; MEDEIROS, A.N.; MADRUGA, M.S.; SHULER, A.R.P. Influência do manejo do rebanho, das condições higiênicas da ordenha e da fase de lactação na composição química do leite de cabras Saanen. Revista Brasileira de Zootecnia, v.36, p.430-437, 2007.

RAPINI, L.S.; CERQUEIRA, M.M.O.P.; CARMO, L.S.; VERAS, J.F.; SOUZA, M.R. Presença de Staphylococcus spp. produtores de enterotoxinas e da toxina da síndrome do choque tóxico em manipuladores de queijo de cabra. Arquivo Brasileiro de Medicina Veterinária e Zootecnia, v.57, p.825-829, 2005.

SAMBROOK, J.; FRITSCH, E.F.; MANIATIS, T. Molecular cloning: a laboratory manual. 2th.ed. New York: Cold Spring Harbor Laboratory Press, 1989. v.2, Cap.14.

THRUSFIELD, M. Epidemiologia veterinária. 2.ed. São Paulo: Roca, 2004. 556p.

VILANOVA, M.; GONÇALVES, M.; OSÓRIO, M.T.M.; ESTEVES, R.; SCHMIDIT V. Aspectos sanitários do úbere e composição química do leite de cabras Saanen. Acta Scientiae Veterinariae, v.36, p.235-240, 2008.

Recebido em 26/9/11

Aceito em 6/2/13 